\title{
Comparison of soil microbial community catabolic diversity between rhizosphere and bulk soil induced by tillage or residue retention
}

\author{
Q.Yang ${ }^{1,2}$, X. Wang ${ }^{1,2}$, Y. Shen ${ }^{1,2 *}$ \\ ${ }^{1}$ State Key Laboratory of Grassland Agro-ecosystems, Lanzhou 730020, China; ${ }^{2}$ College of Pastoral Agriculture Science and \\ Technology, Lanzhou University, Lanzhou; 730020, China, *Corresponding author: yy.shen@lzu.edu.cn
}

\begin{abstract}
The effects of long term no-till and crop residue on soil microbial community catabolic function and relevant carbon cycle in the rhizosphere and bulk soils were assessed in the $10^{\text {th }}$ year of a maize-winter wheat-soybean crop rotation. Conventional and zero tillage were coupled with residue removal and residue retention in a factorial design. Soil microbial community catabolic diversity was determined using Biolog-Eco plate. Average well colour development value (AWCD) of the microbial community in the rhizosphere soil was significantly higher than that in the bulk soil. Soil organic carbon (SOC) and microbial biomass carbon (MB-C) content of rhizosphere soil under both zero tillage and residue removal treatments were significantly higher than those in the bulk soil. Microbes in bulk soil presented a preferential utilization of diverse carbon sources when crop residue was retained. Zero tillage significantly increased the utilization of most carbon sources of microbial in the rhizosphere compared to conventional tillage. Principal component analysis (PCA) of the distribution of carbon substrate utilization for all treatments suggests that the microbial community catabolic diversity is different between the tillage management treatments and between soil sampling positions. Effects of zero tillage and crop residue retention were different with respect to the microbial catabolic diversity in the rhizosphere and the bulk soil.
\end{abstract}

Keywords: Microbial catabolic diversity; soil organic carbon; microbial biomass carbon; conservation tillage; rhizosphere; bulk soil.

\section{Introduction}

Microorganisms in the soil strongly influence soil processes (Garbeva et al., 2004), fulfil key roles in the decomposition of organic matter, the cycling of carbon and nitrogen and the formation and stabilization of soil structure (Loranger-Merciris et al., 2006). Therefore, the constituents of soil microorganisms, such as microbial biomass and microbial community diversity, have often been identified as sensitive indicators of biological indices for maintaining soil health and quality (Bending et al., 2004). The biological properties of rhizosphere soils can differ greatly from those of the bulk soils surrounding rhizosphere (Hinsinger et al., 2009). 
Microbial growth and activity in the rhizosphere is closely related to plant exudates, which are utilized by microorganisms harboured in the rhizosphere region (Lavelle 1997; Walker et al., 2003).

Unsustainable agricultural practices have resulted in extreme soil erosion (Cai et al., 2006; Jiang et al., 2007), which can lead to physical and chemical degradation (Lal et al., 2000). In response to the decline in regional soil quality in the Loess plateau, there has been a gradual shift from conventional tillage towards conservation tillage practices such as zero tillage farming, crop residue retention and crop rotation. These production practices, have resulted in positive effects on crop yield and soil physical and chemical properties (Peixoto et al., 2006), also strongly influence the size, composition, diversity and function of soil microbial communities (Steenwerth et al.,2002; Salles et al., 2006), resulting in significantly altered soil processes. Additionally, residue retention has been used to increase soil organic matter and nutrient contents, improving soil biological characteristics (Roldán et al., 2003; Jordán et al., 2010). Zero tillage has increased soil organic carbon in the surface layer (Melero et al., 2009), including increases of up to $100 \%$ in microbial biomass C (MB-C) in as little as five years (Franchini et al., 2007), and significantly improved soil microbial activity and diversity as well.

Conversely, little is known of the differences of soil carbon cycle and potential microbial metabolic function differences between rhizosphere and bulk soils with differing tillage management practices in the Loess plateau.

Indices of soil microbial community functional diversity in rhizosphere and bulk soils under either conventional or conservation tillage was studied using samples collected under winter wheat crop. The primary objectives of this investigation were: (1) to assess the change of soil carbon cycle and microbial community catabolic diversity between rhizosphere and bulk soil: (2) determine whether different tillage practices have different effects on the soil carbon and soil biochemical status in bulk and rhizosphere soil. effect of different tillage systems on chemical and biochemical properties in the Loess Plateau would be differential in rhizosphere and bulk soil.

\section{Materials and Methods}

\subsection{Site characteristics}

A long-term field experiment was undertaken at Qingyang Loess Plateau field station of Lanzhou University, located in the western Loess Plateau, Gansu Province, China $\left(35^{\circ} 39^{\prime} \mathrm{N}, 107^{\circ} 51^{\prime} \mathrm{E}\right)$. The altitude of the trial site is approximately $1,297 \mathrm{~m}$ above sea level. The climate of the region is complex, with annual average temperatures of $8^{\circ} \mathrm{C}$ to $10^{\circ} \mathrm{C}$. The average growing period is 255 days with 110 frost-free days. The daily temperature above $5^{\circ} \mathrm{C}$ accumulated over a year is $3,446^{\circ} \mathrm{C}$. The area receives an annual precipitation from $480 \mathrm{~mm}$ to $660 \mathrm{~mm}$, most of which falls from July to September. The soil in the trial was a sandy loam of low fertility. Soil organic matter is 1.1$1.2 \%$ and Olsen-P is below $25 \mathrm{mg} \mathrm{kg}^{-1}$. Soil $\mathrm{pH}$ ranges from 8 to 8.5 .

\subsection{The long-term experimental trial}

The long-term conservation tillage trial was established in 2001. The trial consisted of a maize-winter wheat-soybean rotation which was completed every two years. Varieties used were commonly sown by local farmers: maize (Zea mays L.cv Zhongdan No.2); winter wheat (Triticum aestivum L. cv Xifeng No.24); and soybean (Glycine max L. Merr. cv Fengshou No.12).

The experiment was a completely randomized block design with four treatments each replicated four times. Treatments were: conventional tillage to $20 \mathrm{~cm}$ $\left(T_{1}\right)$ or zero tillage $\left(T_{0}\right)$; combined with either crop residue removal $\left(\mathrm{R}_{0}\right)$ or crop residue retention $\left(\mathrm{R}_{1}\right)$ in a $2 \times 2$ factorial design. Tillage occurred in April prior to maize sowing, in September prior to winter wheat sowing and in October after soybean harvest. 
Soybeans were no tilled after winter wheat. All three crop residues were harvested, ground or cut into 5-10 $\mathrm{cm}$ fragments and for the residue retention treatments, all soybean and wheat residues and $50 \%$ of the maize residues were returned to the field. All residues from combining each crop were returned to the appropriate plots. Each plot was $4 \mathrm{~m}$ in width $\times 13 \mathrm{~m}$ in length (52 $\mathrm{m}^{2}$ ), with two metres between blocks and one metre between plots.

The crop rotation of maize-winter wheat-soybean was sown in all plots. Maize was sown in April, with a $50 \mathrm{~cm}$ between rows and $33 \mathrm{~cm}$ between plants, and harvested in mid September. Winter wheat was planted immediately after maize harvest in $15 \mathrm{~cm}$ wide rows at a seeding rate of $225 \mathrm{~kg} \mathrm{ha}^{-1}$ and was harvested in late June or early July the following year. Soybeans were then sown with $25 \mathrm{~cm}$ between rows and plants and harvested in October.

Crop establishment and other agricultural practices were conducted in accordance with common practices of local farmers. All weeds in the field were removed by hand.

Fertilisation of winter wheat was done before sowing with $300 \mathrm{~kg} \mathrm{ha}^{-1}$ diammonium phosphate, (DAP, equivalent to $72.4 \mathrm{~kg} \mathrm{ha}^{-1} \mathrm{~N}$ and $80.2 \mathrm{~kg} \mathrm{ha}^{-1} \mathrm{P}$ ), and at the jointing stage with $\mathrm{N}$ at $69 \mathrm{~kg} \mathrm{ha}^{-1}$ as urea. Before sowing maize $300 \mathrm{~kg} \mathrm{ha}^{-1}$ DAP was applied and $138 \mathrm{~kg}$ $\mathrm{N} \mathrm{ha}^{-1}$ as urea was applied at the booting stage. Before sowing soybean, $27.7 \mathrm{~kg} \mathrm{ha}^{-1}$ of phosphorus was added but no additional nitrogen fertiliser was applied. Annually a six month fallow followed the soybeans after which maize was sown for the beginning of a new cropping cycle. This cropping cycle was repeated four times prior to this study.

\subsection{Soil sampling and analysis}

At winter wheat maturity in 2010 (seeded in 2009), five randomly selected plants in each plot were chosen, soil which adhered to the root hairs after repeated gentle shaking of the whole root system was collected as rhizosphere soil (Lynch, 1990). For bulk soil, five replicated soil samples were collected from the $0-10 \mathrm{~cm}$ soil layer with all surface litter removed, around $5-10 \mathrm{~cm}$ of the plants from which the rhizosphere soil samples were taken. After collection, all rhizosphere samples and bulk soil samples per plot were combined, respectively, and homogenized by removing green matter and coarse particles. Samples were dried at $36^{\circ} \mathrm{C}$, finely ground to pass through a $0.5 \mathrm{~mm}$ sieve and then to be later used for SOC determination. Samples were stored in a freezer and transported to the laboratory within $24 \mathrm{~h}$. Samples were then immediately passed through a $2 \mathrm{~mm}$ sieve and stored at $4^{\circ} \mathrm{C}$ for MB-C and microbial catabolic diversity (Microbial community level physiological profiles) of the soil being analyzed.

Soil organic carbon (SOC) was determined using the modified Walkley-Black procedure (Nelson and Sommers 1982), which involved wet combustion of organic matter with a mixture of potassium dichromate and sulphuric acid at $125^{\circ} \mathrm{C}$. The residual dichromate was titrated against ferrous sulphate to determine SOC.

Soil microbial biomass carbon (MB-C) was estimated using the fumigation extraction method (Brookes et al., 1985). Two $25 \mathrm{~g}$ portions of fresh soil were taken from each of the 16 original soil samples and placed in brown glass tubes. Samples were dampened to approximately $50 \%$ of water-holding capacity and then incubated in the dark at $25^{\circ} \mathrm{C}$ for 10 days to allow equilibration of the soil microbial biomass (Franzluebbers et al., 1996). One portion of each sample was then fumigated for $24 \mathrm{~h}$ at $25^{\circ} \mathrm{C}$ in the dark with ethanol-free chloroform, while the other portion served as the control. Following fumigant removal both fumigated and non-fumigated samples were extracted with $100 \mathrm{~mL}$ of $0.5 \mathrm{M} \mathrm{K}_{2} \mathrm{SO}_{4}$ by horizontal centrifugation and filtration. Organic carbon in the extracts was measured using the dichromate oxidation method (Vance et al., 1987). 


\subsection{Microbial community catabolic diversity}

Microbial community catabolic diversity (microbial community-level physiological profiles CLPP) were determined by Biolog-Eco plates methods (Zak et al. ,1994), that uses colorimetric detection (tetrazolium viole in the plate) to measure microbial respiratory activity in the presence of 32 different single $\mathrm{C}$ substrates, which were sorted as six $\mathrm{C}$ substrates are amino acid, amines, polymers, miscellaneous, carboxylic acids, and carbohydrates. Soil samples, equivalent to $10 \mathrm{~g}$ dry weight, were added to $90 \mathrm{~mL}$ of sterilized saline solution $(0.85 \% \mathrm{NaCl}, \mathrm{w} / \mathrm{v})$ in a 250 $\mathrm{ml}$ flask and centrifuged for $30 \mathrm{~min}$ at $250 \mathrm{rev} \cdot \mathrm{min}^{-1}$. The soil suspension was then subjected to successive tenfold dilutions in sterilized saline solution to a final dilution of 10-3. One hundred and fifty (150) $\mu \mathrm{L}$ aliquot was added into per well in microliter plates (Biolog, Hayward, CA, USA). The plates were incubated at $25^{\circ} \mathrm{C}$ and were measured every $24 \mathrm{~h}$ for $240 \mathrm{~h}$ at $590 \mathrm{~nm}$ by an ELISA plate reader. The values were expressed as the average well colour development (AWCD) for all C sources (Zak et al., 1994) to provide a single value of the substrate utilization activity by the microbial community. AWCD was calculated as follows:

$$
\mathrm{AWCD}=\sum(\mathrm{Ci}-\mathrm{R}) / 31
$$

where $\mathrm{Ci}$ is the absorbance value within each well (optical density measurement), and $\mathrm{R}$ is the colour production of the zero carbon well in plates.

\subsection{Statistical analysis}

Differences in microbial community functional diversity between rhizosphere and bulk soil treatments were statistically analyzed. Significance of tillage and crop residue (main effects and their interactions were calculated by two-way ANOVA, using Genstat Discovery Edition). Differences were considered statistically significance if $p \leq 0.05$. Differences between rhizosphere and bulk soil under alternative treatments were assessed using Student's t-test.
Principal component analysis (PCA) was performed using SPSS (version 13.0, SPSS Inc.)

\section{Results}

\subsection{SOC and MBC content in the rhizosphere and bulk soil}

There was significantly higher SOC in the rhizosphere soil compared with that in the bulk soil, both zero tillage and with residue removal managements (Table 2). The SOC in the rhizosphere soil under zero tillage and residue removal treatments were significantly greater, $12 \%$ and $8 \%$ respectively, when compared to that in the bulk soil. For bulk soil, residue retention significantly increased SOC by $15 \%$ compare to residue removal. The significant changes in SOC stocks of rhizosphere soil were both affected by tillage and residue managements. The SOC under zero tillage was $13 \%$ higher than under conventional tillage, and residue retention was $12 \%$ higher than residue removal $(p<0.001)$ (Table 2).

The MB-C content in the soils was consistent with SOC results, with zero tillage and residue removal treatments significantly increasing the MB-C of the rhizosphere soil compared to the bulk soil. MB-C in the residue retention sample was $14 \%$ higher than residue removal in the bulk soil. There were also significant tillage and residue effects on MB-C of the rhizosphere soil $(p<0.05)($ Table 1$)$.

\subsection{Soil microbial community level physiological profile}

AWCD varied between bulk soil and rhizosphere soil from different treatment groups are shown in Figure 1, AWCD demonstrated a sigmoid pattern for the different treatments as incubation time increased, the overall utilization of all carbon sources was greater in the rhizosphere soil than in the bulk soil across soil management practices. 
The AWCD values of rhizosphere soil under all treatments were significantly higher than those under bulk soil after $48 \mathrm{~h}$ incubation $(p<0.01)$. Residue retention significantly increased AWCD 37\% above that of the residue removal treatments in bulk soil $(p<0.001)$. In the rhizosphere soil, tillage and residue management both significantly influenced the total microbial community activity. Zero tillage increased AWCD 18\% compared to conventional tillage treatment, and residue retention was $3 \%$ higher than residue removal $(p<0.05)$ (Figure 1).

Miscellaneous utilization by microbial was not affected by treatment under the rhizosphere and bulk soil, neither for amines utilization by microbial from rhizosphere soil $(p>0.05)$, in contrast, the utilization rate of amines in bulk soil was 1.5 times that of rhizosphere soil when residues were retained $(p<0.05)$ (Table 3, Table 4).

In bulk soil, residue retention significantly increased $68 \%$ amino acid and $67 \%$ carbohydrate utilization, respectively $(p<0.01)$, under zero tillage management, utilization of polymers was significantly higher $(23 \%)$ than under conventional tillage $(p<0.01)$. In rhizosphere soil, zero tillage significantly increased amino acid $(35 \%)$ and carboxylic acid $(14 \%)$ utilization $(p<0.01)$ compared to conventional tillage. However, the utilization of carboxylic acids under residue retention treatments was $6 \%$ lower than for residue removal treatments (Table 4).

There were interactions between tillage and residue treatments for amine and carboxylic acid utilization under bulk soil samples, and for polymer and carbohydrate utilization under rhizosphere soil (Table 3 ). In bulk soil, zero tillage decreased amine (53\%) and increased carboxylic acid (34\%) utilization compared to conventional tillage. The utilization of amines and carboxylic acids under residue retention was $434 \%$ and $18 \%$ higher than for residue removal treatments (Table 4). There was no change in amines utilization between residue retention and residue removal treatments under zero tillage, however amine utilization with residue retention was 25 times that of residue removal treatment under conventional tillage $(p<0.001)$. Zero tillage significantly increased carboxylic acid utilization
(144\%) over conventional tillage when residue was removal, although no significant differences were found between zero tillage and conventional tillage with the residue retention treatment (Table 5). In rhizosphere soil, the utilization of polymers and carbohydrates under zero tillage was $13 \%$ and $17 \%$ higher than under conventional tillage. Residue retention significantly decreased $27 \%$ polymer utilization and increased $11 \%$ carbohydrate utilization compared to residue removal $(p<0.01)$ (Table 4). The interaction effects on polymer and carbohydrate utilization in the rhizosphere soil were: residue retention significantly increased polymer utilization $(29 \%)$ under zero tillage compared to conventional tillage, while no differences were found under residue removal. Conventional tillage changed the residue effect on carbohydrate utilization, although no differences between residue retention and residue removal were found under zero tillage (Table 5).

Principal component analysis (PCA) was used to identify the major change of carbon utilization during the incubation. The difference in spatial distribution amongst soil samples indicates that the functional diversity of soil microbial communities is influenced by the different treatments, which illustrate that the dispersion of carbon source utilization by soil samples from winter wheat was influenced by tillage, residue and rhizosphere effect. The first principal component axis (PC1) explained $47 \%$ of the overall variance in the data, while the second principal component axis (PC2) explained $17 \%$. Substrate utilization patterns between bulk and rhizosphere soils were largely separated on the PC1 axis. All rhizosphere soil samples were distributed in the positive terminal of $\mathrm{PCl}$ whereas all bulk soil samples were distributed in the negative axis. Both in bulk and rhizosphere soil, the PC2 separated zero tillage from conventional tillage, residue retention from residue removal treatments (Figure 2a). Figure $2 \mathrm{~b}$ showed that the substrates that were utilized more by microorganisms in rhizosphere soil located to the right along PC1 included L-Serine (15), gamma-hydroxybutyrate (23), D-Glucosaminic acid (10) and D-Xylose (8). Conversely, the dominant substrates D-malate (9) was located to the left side along PC 1 for bulk soil. 
Table 1. ANOVA results for soil organic carbon (SOC) and microbial biomass carbon (MB-C) for the $2 \times 2$ factorial experiment.

\begin{tabular}{ccccc}
\hline & \multicolumn{2}{c}{ SOC } & \multicolumn{2}{c}{ MB-C } \\
\cline { 2 - 5 } & Bulk Soil & Rhizosphere soil & Bulk Soil & Rhizosphere soil \\
\hline Tillage effect & ns & $<0.001$ & ns & 0.003 \\
Residue effect & 0.004 & $<0.001$ & 0.031 & 0.002 \\
Tillage x Residue & ns & ns & ns & ns
\end{tabular}

Table 2. Comparison of tillage and residue management treatments of means values (SD) for Soil Organic Carbon (SOC) and Microbial Biomass Carbon (MB-C) in bulk and rhizosphere soils.

\begin{tabular}{ccccc}
\multirow{2}{*}{ Treatment } & \multicolumn{2}{c}{ SOC $\left(\mathrm{g} \mathrm{kg}^{-1}\right)$} & \multicolumn{2}{c}{ MB-C $\left(\mathrm{mg} \mathrm{kg}^{-1}\right)$} \\
\cline { 2 - 4 } & Zero tillage & Conventional tillage & Zero tillage & Conventional tillage \\
\hline Bulk soil & $8.52(0.76)^{\mathrm{b}}$ & $8.06(0.77)^{\mathrm{a}}$ & $164.21(17.35)^{\mathrm{b}}$ & $150.35(13.57)^{\mathrm{a}}$ \\
Rhizosphere soil & $9.58(0.76)^{\mathrm{a}}$ & $8.52(0.45)^{\mathrm{a}}$ & $179.26(12.84)^{\mathrm{a}}$ & $162.23(12.52)^{\mathrm{a}}$ \\
& Residue removal & Residue retention & Residue removal $^{\mathrm{a}}$ & Residue retention \\
Bulk soil & $7.71(0.48)^{\mathrm{b}}$ & $8.87(0.61)^{\mathrm{a}}$ & $147.18(14.81)^{\mathrm{b}}$ & $167.38(12.57)^{\mathrm{a}}$ \\
Rhizosphere soil & $8.53(0.45)^{\mathrm{a}}$ & $9.57(0.78)^{\mathrm{a}}$ & $161.44(10.97)^{\mathrm{a}}$ & $180.05(13.16)^{\mathrm{a}}$ \\
\hline
\end{tabular}

Table 3. ANOVA results for six of $\mathrm{C}$ substrate-utilisation by miccrobial respiration for the $2 \times 2$ factorial experiment.

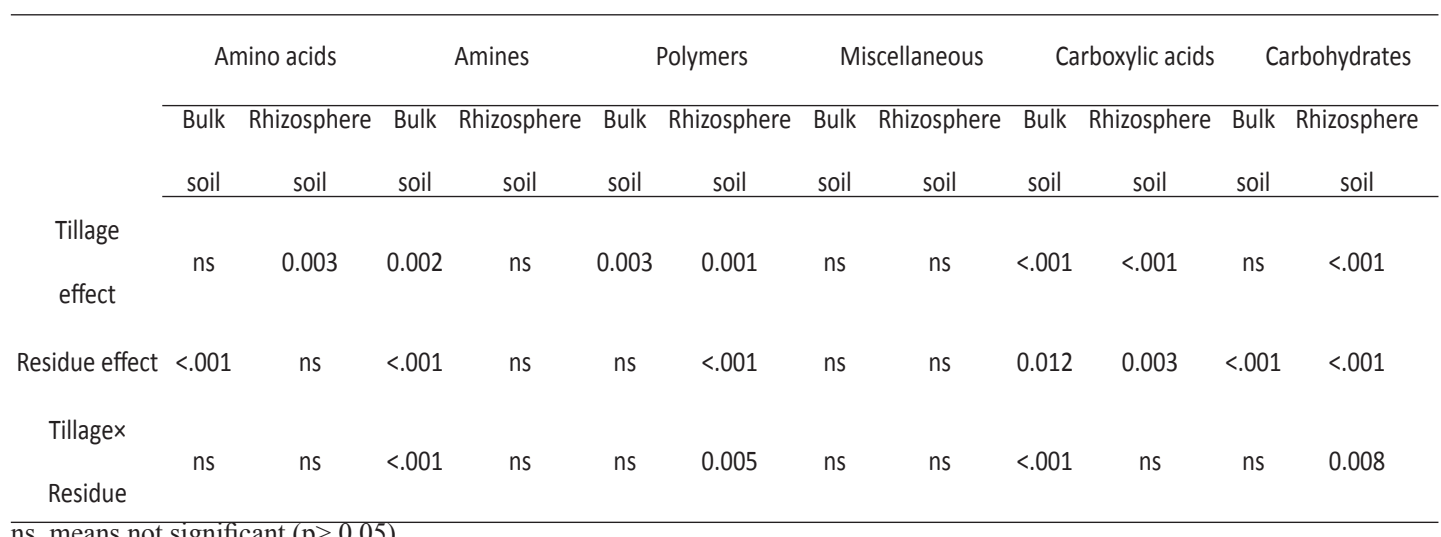


Table 4. Comparison of tillage and residue management treatments of means values (SD) for six types of substrateutilisation by soil microbial communities at $144 \mathrm{~h}$ incubation in bulk and rhizosphere soils

\begin{tabular}{|c|c|c|c|c|c|c|c|c|c|c|c|c|}
\hline \multirow{3}{*}{ Treatment } & \multicolumn{2}{|l|}{$\begin{array}{c}\text { Amino } \\
\text { acids }\end{array}$} & \multicolumn{2}{|l|}{ Amines } & \multicolumn{2}{|c|}{ Polymers } & \multicolumn{2}{|c|}{ Miscellaneous } & \multicolumn{2}{|c|}{ Carboxylic acids } & \multicolumn{2}{|c|}{ Carbohydrates } \\
\hline & Zero & Conventional & Zero & Conventional & Zero & Conventional & Zero & Conventional & Zero & Conventional & Zero & Conventional \\
\hline & tillage & tillage & tillage & tillage & tillage & tillage & tillage & tillage & tillage & tillage & tillage & tillage \\
\hline Bulk soil & $0.90(0.03)^{b}$ & $0.91(0.01)^{b}$ & $0.22(0.02)^{b}$ & $0.47(0.04)^{\mathrm{a}}$ & $0.97(0.02)^{b}$ & $0.79(0.01)^{b}$ & $0.61(0.15)^{b}$ & $0.71(0.01)^{\mathrm{a}}$ & $0.82(0.03)^{\mathrm{b}}$ & $0.61(0.02)^{b}$ & $1.33(0.07)^{b}$ & $1.40(0.06)^{b}$ \\
\hline \multicolumn{13}{|c|}{ Rhizosphere } \\
\hline \multirow{3}{*}{ soil } & $1.43(0.07)^{\mathrm{a}}$ & $1.06(0.01)^{a}$ & $0.33(0.02)^{\mathrm{a}}$ & $0.37(0.01)^{\mathrm{a}}$ & $1.69(0.03)^{\mathrm{a}}$ & $1.50(0.01)^{a}$ & $0.93(0.04)^{a}$ & $0.99(0.03)^{\mathrm{a}}$ & $1.18(0.01)^{a}$ & $1.04(0.01)^{\mathrm{a}}$ & $2.08(0.02)^{\mathrm{a}}$ & $1.78(0.03)^{a}$ \\
\hline & Residue & Residue & Residue & Residue & Residue & Residue & Residue & Residue & Residue & Residue & Residue & Residue \\
\hline & removal & retention & removal & retention & removal & retention & removal & retention & removal & retention & removal & retention \\
\hline Bulk soil & $0.67(0.02)^{b}$ & $1.13(0.02)^{\mathrm{a}}$ & $0.11(0.02)^{b}$ & $0.58(0.04)^{\mathrm{a}}$ & $0.85(0.04)^{b}$ & $0.92(0.01)^{b}$ & $0.59(0.11)^{b}$ & $0.72(0.04)^{b}$ & $0.65(0.02)^{b}$ & $0.77(0.03)^{b}$ & $1.02(0.03)^{b}$ & $1.71(0.05)^{b}$ \\
\hline \multicolumn{13}{|l|}{ Rhizosphere } \\
\hline soil & $1.17(0.01)^{\mathrm{a}}$ & $1.32(0.08)^{\mathrm{a}}$ & $0.31(0.03)^{\mathrm{a}}$ & $0.39(0.03)^{\mathrm{b}}$ & $1.85(0.01)^{\mathrm{a}}$ & $1.34(0.02)^{a}$ & $0.91(0.04)^{\mathrm{a}}$ & $1.01(0.03)^{\mathrm{a}}$ & $1.15(0.01)^{\mathrm{a}}$ & $1.07(0.01)^{a}$ & $1.82(0.01)^{\mathrm{a}}$ & $2.03(0.03)^{\mathrm{a}}$ \\
\hline
\end{tabular}

Table 5. The interaction of Amine and Carboxylic acids utilization from bulk soil, Polymers and Carbohydrates utilization from rhizosphere soil for four tillage $\mathrm{x}$ residue measurements, the means values (SD) of conventional tillage $\mathrm{x}$ residue removal, conventional tillage $\mathrm{x}$ residue retention, zero tillage $\mathrm{x}$ residue removal and zero tillage $\mathrm{x}$ residue retention.

\begin{tabular}{|c|c|c|c|c|}
\hline \multirow{2}{*}{ Treatment } & \multicolumn{2}{|c|}{ Bulk soil } & \multicolumn{2}{|c|}{ Rhizosphere soil } \\
\hline & Amines & Carboxylic acids & Polymers & Carbohydrates \\
\hline $\begin{array}{l}\text { Conventional tillage } \\
\mathrm{x} \text { Residue removal }\end{array}$ & $0.04(0.02)$ & $0.38(0.01)$ & $1.82(0.40)$ & $1.62(0.37)$ \\
\hline $\begin{array}{l}\text { Conventional tillage } \\
\text { xResidue retention }\end{array}$ & $0.91(0.19)$ & $0.84(0.18)$ & $1.17(0.32)$ & $1.94(0.40)$ \\
\hline $\begin{array}{c}\text { Zero tillage } \\
\text { x Residue removal }\end{array}$ & $0.18(0.04)$ & $0.93(0.20)$ & $1.87(0.33)$ & $2.03(0.59)$ \\
\hline $\begin{array}{c}\text { Zero tillage } \\
\text { xResidue retention }\end{array}$ & $0.26(0.10)$ & $0.71(0.10)$ & $1.51(0.37)$ & $2.12(0.39)$ \\
\hline$L S D$ & 0.14 & 0.14 & 0.12 & 0.10 \\
\hline
\end{tabular}




\section{Discussion}

In this study we investigated microbial processes in the rhizosphere and bulk soil under different tillage managements. We correctly hypothesised that great differences would exist in soil carbon cycling and microbial community catabolic diversity between the rhizosphere and the bulk soil, and that differences in soil carbon content and biochemical properties under the tillage and residue managements would impact rhizosphere effect.

After ten years of conversation tillage practices in a crop rotation system, soil physical and chemical properties were improved, leading to no yields penalty and greater water use efficiency (WUE) in this rotation system (Duan et al., 2010). Soil properties which showed improvement included soil organic matter (SOM), total nitrogen (TN), phosphorus $(\mathrm{P})$ content, bulk density, porosity, and soil aggregate size (data not shown), consistent with prior investigations of conservation tillage effects (Peixoto et al., 2006; Thomas et al., 2007). The effects of tillage and residue on the diversity and function of soil microbial communities was significant, which was consistent with previous study (Meriles et al., 2009; González-Chávez et al., 2010).

Average well colour development, reflecting the oxidative potential of microorganisms, was used to calculated microbial activity as a whole, and also relates positively to the species number and to soil microbial community size (Chen et al., 2007). The catabolic functional diversity of microbial communities in the rhizosphere was higher than that of in bulk soil, consistent with the results in paddy rice (Chen et al. 2008), This may be due to the higher (or diversity of) carbon resources in the rhizosphere soil, which is considered as the driving force for microbial density and activity (Bowen \& Rovira 1999; Lugtenberg \& Dekkers 1999). A gelatinous film on the root surface, which is a primary source of nutrients and energy amongst soil microbes, has been reported in a variety of ecosystems (Salt et al., 1998). However, long-term increased SOC by $15 \%$, MB-C by $14 \%$ and total soil bio-activity by $37 \%$ in bulk soil, due to the large input of organic tillage and residue effects on $\mathrm{C}$ utilization pattern and soil microbial functional diversity differ from rhizosphere to bulk soil. (Lou et al., 2011) reported that residue retention increased SOC by $15 \%$, MB-C by $14 \%$ and total soil bio-activity by $37 \%$ in bulk soil, due to the large input of organic matter from crop residue decomposition, an important renewable resource, containing abundant $\mathrm{C}, \mathrm{N}, \mathrm{P}, \mathrm{K}$ and micro-nutrients. Bulk soil microorganism processes are influenced primarily by plant litters (Vance \& Chapin III 2001), and differences in microbial functional diversity can be attributed to variations in plant litter quality and substrate inputs (Myers et al. ,2001). Conversely, functions of the rhizosphere are of central importance to soil biological properties and plant health (Lynch 1990; Chen et al., 2001), and are regulated by the activity of microorganisms in root systems. SOM decomposition constantly occurs with plant roots, thereby inevitably becoming entangled with both the soil component and the plant component. Any environmental conditions that affect either plant functions or soil functions, or both, inevitably modulate root effects on SOM decomposition (Cheng \& Kuzyakov 2005). Therefore both tillage and residue management have significant impacts on rhizosphere soil carbon cycling and microbial function.

Alternative tillage and residue managements will affect microbial communities resulting in different catabolic functional diversity and depending on the location of soil in relation to plant roots, certain C-substrates will be used more than others. In the bulk soil when residue was retained, microbes displayed preferential utilization of four carbon sources, rather than polymers and miscellaneous sources. During the residue decomposition low-molecular-weight aliphatic carboxylic acids and their anions (LACAs) are released when incorporated into soil (Tian et al., 1992; Tang et al., 1999), which depending on plant species, sources of nitrogen applied, stage of plant growth, and edaphic and climatic conditions can differ considerably (Xu et al.,2006).

In the rhizosphere, zero tillage significantly increased utilization of most carbon sources compared to conventional tillage. Zero tillage results in significant 
improvements in water retention, aggregate stability, temperature and other parameters compared to conventional tillage (Rhoton 2000). These improvements in soil quality may also preserve nutrient resources originating from plant root exudation and includes sugars, amino acids, organic acids and vitamins, which serve as substrates for microorganisms (Chen et al., 2006). In our study, more carboxylic acid utilization was found in rhizosphere soil which had received zero tillage management. Carboxylic acids have been associated with plant root exudation under stress, (i.e. malic acid is known to increase in plants when stressed due to oxygen deficiency (Breitkreuz et al., 2003). Neither tillage practices, nor residue practices had a significant effect on the utilization of miscellaneous carbon sources in either rhizosphere or bulk soil, the miscellaneous carbon source group includes substrates that may be degraded very slowly by most soil microbes, only a few bacteria, such as Bacillus macerans, are able to convert a-cyclodextrin (Nam et al., 2001). Difference in the distribution of carbon substrate utilization between the rhizosphere and the bulk soil across different management practices was found. PCA revealed tillage practices were able to illustrate the difference of microbial communities in rhizosphere and bulk soil, consistent with prior research (Peixoto et al., 2006; Meriles et al., 2009; González-Chávez et al., 2010).

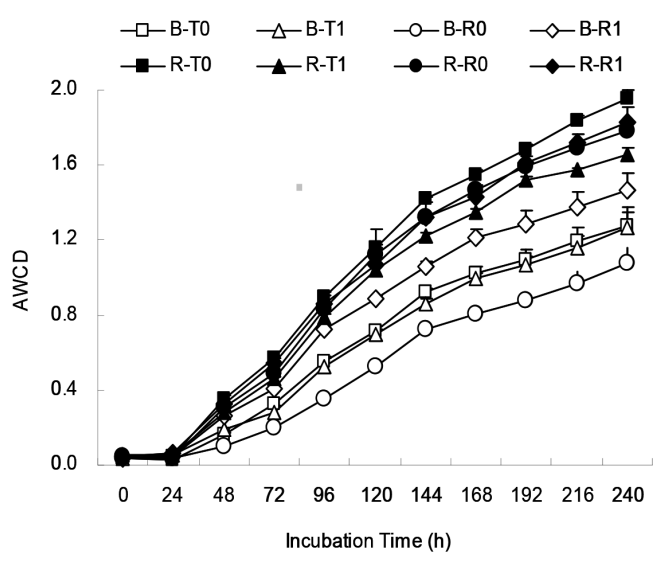

Figure 1. Variation of average well colour development (AWCD) values by microbial under different tillage and crop residue treatments from bulk soil (B) and rhizosphere soil (R) samples, as a function of incubation time, sampled at winter wheat harvest from a 10th year of a continuous 2-yr maize wheat - soybean rotation on the Loess Plateau, China. $\mathrm{T}_{0}$ : zero tillage; $\mathrm{T}_{1}$ : conventional tillage (tilled twice a year to $20 \mathrm{~cm}$ ); $\mathrm{R}_{0}$ : crop residues removal after crop harvest; $\mathrm{R}_{1}$ : crop residues retention after crop harvest. Error bars indicate SD of replicates.
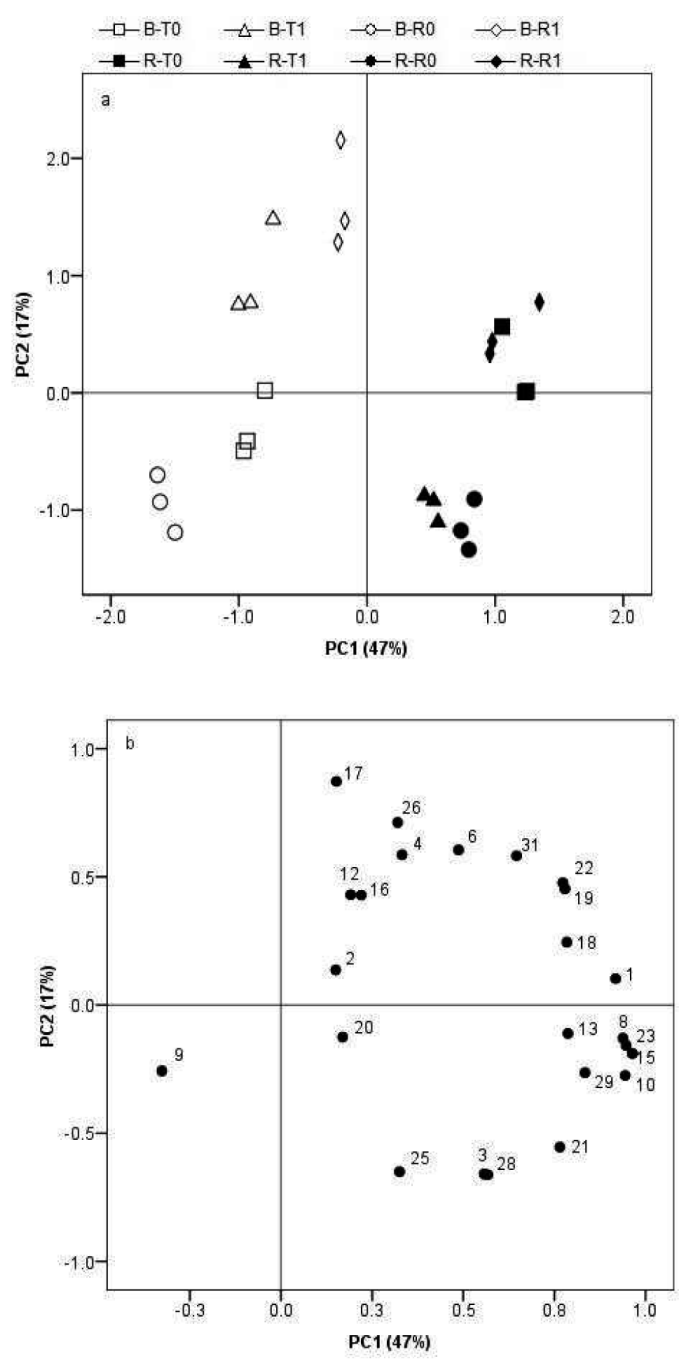
Figure 2. (a) Principal component analysis (PCA) of single carbon source utilisation patterns by microbial from bulk soil (B) and rhizosphere soil (R) samples at $144 \mathrm{~h}$ incubation time across different tillage and crop residue treatments, sampled at winter wheat harvest in a $10^{\text {th }}$ year of a continuous 2-yr maize-wheat-soybean rotation on the Loess Plateau, China. (b) Loadings of the individual carbon source utilisation from the PCA of principal components 1 and 2. The percentage of variation is expressed along the two main axes. PC1: the first principal component; PC2: the second principal component. $\mathrm{R}_{0}$ : crop residues removal after harvest; $\mathrm{R}_{1}$ : crop residues retention after crop harvest. 1: a-D-Glucose1-Phosphate; 2: 2-hydroxy benzoic acid; 3: 4-Hydroxy benzoic acid; 4: D,L-a-Glycerol Phosphate; 6: D-galactonic acid lactone; 8: D-Xylose; 9: D-malate; 10: D-Glucosaminic acid; 12: i-Erythritol; 13: L-Phenylalanine; 15: L-Serine; 16: L-Threonine; 17: L-asparagine; 18: N-Acetyl-DGlucosamine; 19: $\alpha$-D-Latose; 20: a-Ketobutyric acid; 21: a-cyclodextrin; 22: $\beta$-Methyl-D-Glucoside; 23: gammahydroxybutyrate; 25: Pyruvic Acid Methyl Ester; 26: Putrescine; 28: Glycogen; 29: Tween 40; 31: Itaconic acid.

\section{Conclusions}

This study focused on the long-term effects of tillage and residue retention on soil carbon cycling and soil microbial catabolic diversity between rhizosphere and bulk soils in the Loess Plateau. It clearly demonstrates that the soil microbial catabolic diversity in rhizosphere soil were significantly higher than bulk soil under winter wheat. Bulk soil microbes displayed a preferential utilization of diverse carbon sources when crop residue was retained, however, rhizosphere soil microbes significantly increased the utilization of most carbon sources by applying zero tillage. The effect of different tillage systems on soil carbon and microbial community level physiological profiles in the Loess Plateau was influenced by rhizosphere effects.

\section{Acknowledgements}

This research is supported by the Keygrant Project of Chinese Ministry of Education (No313028), the National Basic Research Programme of China (2007CB106804), the Australian Centre for International Agricultural Research project (LWR/2007/191) and the Fundamental Research Funds for the Central Universities of China (lzujbky-2012-218).

\section{References}

Bending, G.D., Turner, M.K., Rayns, F., Marx, M.C., Wood, M. 2004. Microbial and biochemical soil quality indicators and their potential for differentiating areas under contrasting agricultural management regimes. Soil Biology and Biochemistry. 36, 1785-1792.

Bowen, G.D., Rovira, A.D. 1999. The Rhizosphere and Its Management To Improve Plant Growth. In: Donald LS ed. Advances in Agronomy, Academic Press. Pp. 1-102.

Breitkreuz, K.E., Allan, W.L., Van Cauwenberghe,OR., Jakobs, C., Talibi, D., André, B., Shelp, B.J. 2003. A Novel $\gamma$-Hydroxybutyrate Dehydrogenase: Identification and expression of an arabidopsis cDNA and potential role under oxygen deficiency. Journal of Biological Chemistry. 278, 41552-41556.

Brookes, P.C, Landman, A., Pruden, G., Jenkinson, D.S. 1985. Chloroform fumigation and the release of soil nitrogen: A rapid direct extraction method to measure microbial biomass nitrogen in soil. Soil Biology and Biochemistry. 17, 837-842.

Cai, D.X., Ke, J., Wang, X.B., Hoogmoed, W.B, ,Oenema, O., Perdok, U.D. 2006. Conservation tillage for dryland farming in China. Proceedings of the 17th ISTRO conference, Kiel, Germany, August 28th - Sept. 3rd., 2006. Pp. 1627-1633. 
Chen, J., Zhuang, X., Xie, H., Bai. Z., Qi, H., Zhang, H. 2007. Associated impact of inorganic fertilizers and pesticides on microbial communities in soils. World Journal of Microbiology and Biotechnology. 23, 23-29.

Chen, M.C., Wang, M.K., Chiu, C.Y, Huang, P.M., King, H.B. 2001. Determination of low molecular weight dicarboxylic acids and organic functional groups in rhizosphere and bulk soils of Tsuga and Yushania in a temperate rain forest. Plant and Soil 231, 37-44.

Chen, X.P., Kong, W.D., He, J.Z., Liu, W.J., Smith, S.E., Smith, F.A., Zhu, Y.G. 2008. Do water regimes affect iron-plaque formation and microbial communities in the rhizosphere of paddy rice? .Journal of Plant Nutrition and Soil Science. 171, 193-199.

Chen, Y.M., Wang, M.K., Zhuang, S.Y.,Chiang, P.N 2006. Chemical and physical properties of rhizosphere and bulk soils of three tea plants cultivated in Ultisols. Geoderma. 136, 378-387.

Cheng, W.X., Kuzyakov, Y. 2005. Root effects on soil organic matter decomposition. In: Zobel RW, Wright SF ed. Roots and soil management: interactions between roots and the soil Madison American Society of Agronomy. Pp. 119-143.

Duan, T., Shen, Y., Facelli, E., Smith, S.E., Nan, Z. 2010. New agricultural practices in the Loess Plateau of China do not reduce colonisation by arbuscular mycorrhizal or root invading fungi and do not carry a yield penalty. Plant and Soil 331, 265-275.

Franchini, J.C., Crispino, C.C.,Souza, R.A.,Torres ,E, Hungria, M. 2007. Microbiological parameters as indicators of soil quality under various soil management and crop rotation systems in southern Brazil. Soil and Tillage Research. 92, 1829.
Franzluebbers, A.J., Haney R.L., Hons F.M., Zuberer, D.A. 1996. Determination of Microbial Biomass and Nitrogen Mineralization following Rewetting of Dried Soil. Soil Science Society of America Journal. 60, 1133-1139.

Garbeva, P., van Veen, J.A., van Elsas, J.D 2004. Microbial Diversity IN Soil: Selection of Microbial Populations by Plant and Soil Type and Implications for Disease Suppressiveness. Annual Review of Phytopathology. 42, 243-270.

González-Chávez,Md CA., Aitkenhead-Peterson, J.A, Gentry, T.J, Zuberer, D, Hons F, Loeppert, R. 2010. Soil microbial community, C, N, and P responses to long-term tillage and crop rotation. Soil and Tillage Research. 106, 285-293.

Hinsinger, P., Bengough, A.G., Vetterlein, D., Young, I.M. 2009. Rhizosphere: biophysics, biogeochemistry and ecological relevance. Plant and Soil. 321, 117-152.

Jiang, J.P., Xiong, Y.C., Jia, Y., Li, F.M., Xu, J.Z, Jiang, H.M. 2007. Soil Quality Dynamics Under Successional Alfalfa Field in the Semi-arid Loess Plateau of Northwestern China. Arid Land Research and Management .21, 287-303.

Jordán,A., Zavala, L.M., Gil, J. 2010. Effects of mulching on soil physical properties and runoff under semi-arid conditions in southern Spain. Catena. 81, 77-85.

Lal, R., Ahmadi, M., Bajracharya. R.M. 2000. Erosional impacts on soil properties and corn yield on Alfisols in central Ohio. Land Degradation \& Development. 11, 575-585.

Lavelle, P. 1997. Faunal Activities and Soil Processes: Adaptive Strategies That Determine Ecosystem Function. In: Begon M, Fitter AH ed. Advances in Ecological Research, Academic Press. Pp. 93132. 
Loranger-Merciris, G., Barthes, L., Gastine,A., Leadley, P. 2006. Rapid effects of plant species diversity and identity on soil microbial communities in experimental grassland ecosystems. Soil Biology and Biochemistry. 38, 2336-2343.

Lou, Y, Liang, W., Xu, M., He, X., Wang, Y., Zhao, K. 2011. Straw coverage alleviates seasonal variability of the topsoil microbial biomass and activity. Catena. 86, 117-120.

Lugtenberg, B.J.J., Dekkers, L.C. 1999. What makes Pseudomonas bacteria rhizosphere competent?. Environmental Microbiology. 1, 9-13.

Lynch, J.M. 1990. . Soil Rhizosphere. Soil Rhizosphere, John Wiley and Sons.

Melero, S., López-Garrido, R., Murillo, J.M, Moreno, F. 2009. Conservation tillage: Short- and long-term effects on soil carbon fractions and enzymatic activities under Mediterranean conditions .Soil Till. Res. 104, 292-298

Meriles, J.M., Vargas Gil, S., Conforto, C, Figoni, G., Lovera, E., March, G.J, Guzmán, C.A. 2009. Soil microbial communities under different soybean cropping systems: Characterization of microbial population dynamics, soil microbial activity, microbial biomass, and fatty acid profiles. Soil and Tillage Research .103, 271-281.

Myers, R.T., Zak, D.R., White, D.C., Peacock, A. 2001. Landscape-Level Patterns of Microbial Community Composition and Substrate Use in Upland Forest Ecosystems. Soil Science Society of America Journal. 65, 359-367.

Nam, SW., Park, H.Y., Kim, J.H., Seo, J.H., Han, N.S., Kim, B.W. 2001. Expression of Bacillus macerans cyclodextrin glucanotransferase gene in Saccharomyces cerevisiae. Biotechnology Letters. $23,727-730$.
Nelson, D.W., Sommers, L.E. ed. 1982. Total carbon, organic carbon, and organic matter. Madison, American Society of Agronomy. 539-579 p.

Peixoto, R.S., Coutinho, H.L.C., Madari, B., Machado, P.L.O.A., Rumjanek, N.G., Van Elsas, J.D., Seldin ,L, Rosado. A.S. 2006. Soil aggregation and bacterial community structure as affected by tillage and cover cropping in the Brazilian Cerrados. Soil and Tillage Research. 90, 16-28.

Rhoton, F.E. 2000. Influence of time on soil response to no-till practices. Soil Science Society of America Journal. 64, 700-709.

Roldán, A., Caravac, F., Hernández, M.T., García, C., Sánchez-Brito, C., Velásquez, M., Tiscareño, M. 2003. No-tillage, crop residue additions, and legume cover cropping effects on soil quality characteristics under maize in Patzcuaro watershed (Mexico). Soil and Tillage Research. 72, 65-73.

Salles, J.F., van Elsas, J.D., van Veen, J.A. 2006. Effect of Agricultural Management Regime on Burkholderia Community Structure in Soil. Microbial Ecology. 52, 267-279.

Salt, DE., Smith, R.D., Raskin, I. 1998. Phytoremediation. Annual Review of Plant Physiology and Plant Molecular Biology. 49, 643-668.

Steenwerth, K.L., Jackson, L.E., Calderón, F.J., Stromberg, M.R., Scow, K.M. 2002. Soil microbial community composition and land use history in cultivated and grassland ecosystems of coastal California. Soil Biology and Biochemistry. 34, 1599-1611.

Tang, C., Sparling, GP., Mclay., C.D.A., Raphael ,C. 1999. Effect of short-term legume residue decomposition on soil acidity. Australian Journal of Soil Research. 37, 561-573.

Thomas ,GA., Dalal, R.C., Standley, J. 2007. No-till effects on organic matter, $\mathrm{pH}$, cation exchange 
capacity and nutrient distribution in a Luvisol in the semi-arid subtropics. Soil and Tillage Research. 94, 295-304.

Tian, G., Kang, BT, Brussaard, L. 1992. Biological effects of plant residues with contrasting chemical compositions under humid tropical conditionsDecomposition and nutrient release. Soil Biology and Biochemistry. 24, 1051-1060.

Vance, E.D., Chapin, III. F.S. 2001. Substrate limitations to microbial activity in taiga forest floors. Soil Biology and Biochemistry. 33, 173-188.

Vance, E.D., Brookes, P.C., Jenkinson, D.S. 1987. An extracted method for measuring soil microbial biomass C. Soil Biology and Biochemistry. 19, 703-707.
Walker, T.S., Bais, H.P., Grotewold, E, Vivanco, J.M. 2003. Root e.xudation and rhizosphere biology. Plant physiology. 132, 44-51.

Xu, J.M, Tang C., Chen, Z.L. 2006. Chemical composition controls residue decomposition in soils differing in initial $\mathrm{pH}$. Soil Biology and Biochemistry. 38, 544-552.

Zak, J.C. Willig, M.R, Moorhead, D.L, Wildman, H.G. 1994. Functional diversity of microbial communities: A quantitative approach. Soil Biology and Biochemistry. 26, 1101-1108 